\title{
Plasmodium infection alters Anopheles gambiae detoxification gene expression
}

Rute C Félix ${ }^{1}$, Pie Müller ${ }^{2,3,4}$, Vera Ribeiro ${ }^{5}$, Hilary Ranson², Henrique Silveira ${ }^{\text {* }}$

\begin{abstract}
Background: Anopheles gambiae has been shown to change its global gene expression patterns upon Plasmodium infection. While many alterations are directly related to the mosquito's innate immune response, parasite invasion is also expected to generate toxic by-products such as free radicals. The current study aimed at identifying which loci coding for detoxification enzymes are differentially expressed as a function of Plasmodium berghei infection in midgut and fat body tissues.

Results: Using a custom-made DNA microarray, transcript levels of 254 loci primarily belonging to three major detoxification enzyme families (glutathione S-transferases, cytochrome P450 monooxygenases and esterases) were compared in infected and uninfected mosquitoes both during ookinete invasion and the release of sporozoites into the hemocoel. The greatest changes in gene expression were observed in the midgut in response to ookinete invasion. Interestingly, many detoxification genes including a large number of P450s were down-regulated at this stage. In the fat body, while less dramatic, gene expression alterations were also observed and occurred during the ookinete invasion and during the release of sporozoites into the hemocoel. While most gene expression changes were tissue-related, CYP6M2, a CYP previously associated with insecticide resistance, was over-expressed both in the midgut and fat body during ookinete invasion.
\end{abstract}

Conclusions: Most toxicity-related reactions occur in the midgut shortly after the ingestion of an infected blood meal. Strong up-regulation of CYP6M2 in the midgut and the fat body as well as its previous association with insecticide resistance shows its broad role in metabolic detoxification.

\section{Background}

The mosquito Anopheles gambiae is the main malaria vector in sub-Saharan Africa. Resistance to anti-malaria drugs and insecticides together with the lack of vaccines highlight the need for novel strategies in malaria control. Such a strategy could be the interruption of the transmission cycle within the mosquito.

The mosquito becomes infected with the malaria parasite by taking a blood meal. The blood meal itself brings metabolic changes and induces a state of oxidative stress $[1,2]$. This is further increased by the presence of Plasmodium parasites in the blood meal [3]. During mosquito response to infection, active nitrogen and oxygen radicals are produced to contain Plasmodium infection $[1,3]$. These products may represent potential oxidative

\footnotetext{
* Correspondence: hsilveira@ihmt.unl.pt
${ }^{1}$ Centro de Malária e Outras Doenças Tropicais, UEl Malária, Instituto de

* Correspondence: hsilveira@ihmt.unl.pt
'Centro de Malária e Outras Doenças Tropicais, UEl Malária, Instituto de Higiene e Medicina Tropical, Universidade Nova de Lisboa, Rua da Junqueira, 96, 1349-008 Lisbon, Portugal
}

(c) 2010 Félix et al; licensee BioMed Central Ltd. This is an Open Access article distributed under the terms of the Creative Commons Attribution License (http://creativecommons.org/licenses/by/2.0), which permits unrestricted use, distribution, and reproduction in any medium, provided the original work is properly cited. cation enzymes. For example several glutathione Stransferases (GSTs) have peroxidase activity and some can also metabolise reactive $\alpha, \beta$-aldehydes [4]. GST expression can also be induced by reactive oxygen species (ROS) [5,6]. While GSTs help to eliminate ROS, cytochrome P450 monooxygenases (CYP) may actually contribute towards its generation [7].

Although transcription alteration of detoxification genes in response to bacteria and Plasmodium [8-10] has been described, the nature of this response hasn't been fully discussed. In this study we describe the impact of $P$. berghei infection at two time points (1 day and 11 days post infection) on the expression of detoxification genes in the midgut and fat body. We identified several genes, previously implicated in the detoxification of xenobiotics, which are differentially expressed in relation to parasite infection in the midgut and fat body. 
The possible role of detoxification enzymes in modulating malaria transmission is discussed.

\section{Results and Discussion Microarray}

Tissues for microarray analyses were collected at two critical time points of the Plasmodium cycle in the mosquito host: 1 day following the blood meal, during which parasites invade the midgut epithelium, and 11 days after the blood meal when sporozoites are starting to be released to the hemolymph, as demonstrated by detection of parasite's DNA in the hemolymph (data not shown). The mosquitoes were fed on mice that were either infected with the parasite or uninfected. The success of infection was indirectly confirmed by randomly selecting up to 19-44 mosquitoes that were screened for the presence of oocysts (see Table S1 in Additional file 1). Most of the mosquitoes were found to be positive $(70.5 \%$ to $84 \%)$ and hence it can be assumed that the tissues used in the gene expression studies were infected too.

The microarray experiment was developed to answer the following questions, regarding midgut and fat body tissues:

1. which genes respond to Plasmodium midgut epithelium invasion (1 day post blood meal)

2. which genes respond to the release of sporozoites into the hemolymph (11 days post blood meal), and 3 . which genes respond differently between the two events (interaction term).

In the microarray analysis 146 loci were differentially expressed in at least one of the comparisons made. The results for all comparisons are given in Table S2 (Additional file 2). The microarray results were validated by comparing the mean values for the expression data $\left(\log _{2}\right.$ ratio) for genes from three independent replicates obtained by microarray analysis with the corresponding mean expression values obtained with the multiplex quantitative RT-PCR. The Pearson correlation coefficient $(P=0.884$ for midgut, $P=0.85$ for fat body) demonstrates a high degree of correlation between the two methods (see Figure S1 in Additional file 3).

\section{Genes differentially expressed in infected versus uninfected mosquitoes at day 1 post blood meal}

At day 1 post blood meal more changes were observed in the midgut as compared to the fat body. While in the midgut 54 genes were differentially expressed, only 13 were different in the fat body (Figure 1, Table 1). In the midgut, 22 CYPs were differentially expressed with the majority (17) being down-regulated. In the fat body, five out of the six CYPs differentially expressed in response to Plasmodium infection were up-regulated. The vast majority of these differentially expressed CYPs belong to families primarily associated with detoxification roles (e.g. CYP4, CYP6 and CYP9) rather than families implicated in hormone biosynthetic pathways [11]. Similarly in the GST family the two classes primarily associated with xenobiotic detoxification, Delta and Epsilon [4], were generally repressed in response to parasite infection with the notable exception of GSTD5 which was strongly up-regulated $(>8.5 \times)$ in infected vs. uninfected midguts.

In both $A$. gambiae and A. stephensi, Plasmodium parasite invasion induces an increase of nitric oxide synthase (NOS) expression and in turn an increase in nitric oxide (NO) and NO metabolites [12-15]. NO has been shown to down regulate CYP gene expression in other organisms [16]. We hypothesize therefore that the observed down-regulation of CYPs in the midgut may also be linked to increased levels of NO.

Of the up-regulated CYPs, CYP6M2 showed the greatest response to infection (Figure 2). This gene has already been reported to be over-expressed in response to $P$. berghei infection [10] and implicated in resistance to pyrethroid insecticides $[17,18]$. One possible explanation for this up-regulation is a response to an endogenous mediator increased upon the infection process. As an example, prostaglandins have been shown to induce expression of CYPs in human liver cells [19].

Superoxide dismutases constitute part of the first line of defence against ROS and reactive nitrogen oxide species (RNOS) [1]. However, SOD2 was down-regulated 1 day post infection suggesting that down-regulation of oxidative stress response genes could be part of the defence response triggered by parasite invasion. A similar mechanism has been described for other oxidative stress response genes such as catalase in response to Plasmodium invasion [3].

Cytoskeleton reorganization and up-regulation of genes related to folding and movement of microtubules suggest that cytoskeleton dynamics and remodelling function as key elements of Plasmodium invasion of the Anopheles midgut [2]. This epithelium rearrangement is a robust molecular response to ookinetes penetration. In a whole genome microarray study seven tubulins were differentially up-regulated during the invasion period [2]. Here too, three cytoskeletal genes represented on the Detox array, tubulin $B$, tubulin $A$ and actin, were up-regulated at day 1 post infection (1.85, 8.76 and 1.44 fold, respectively). In mammals, microtubule disruption leads to down-regulation of several CYPs [20] and perhaps similar responses also lead to down-regulation of CYPs during parasite invasion. 


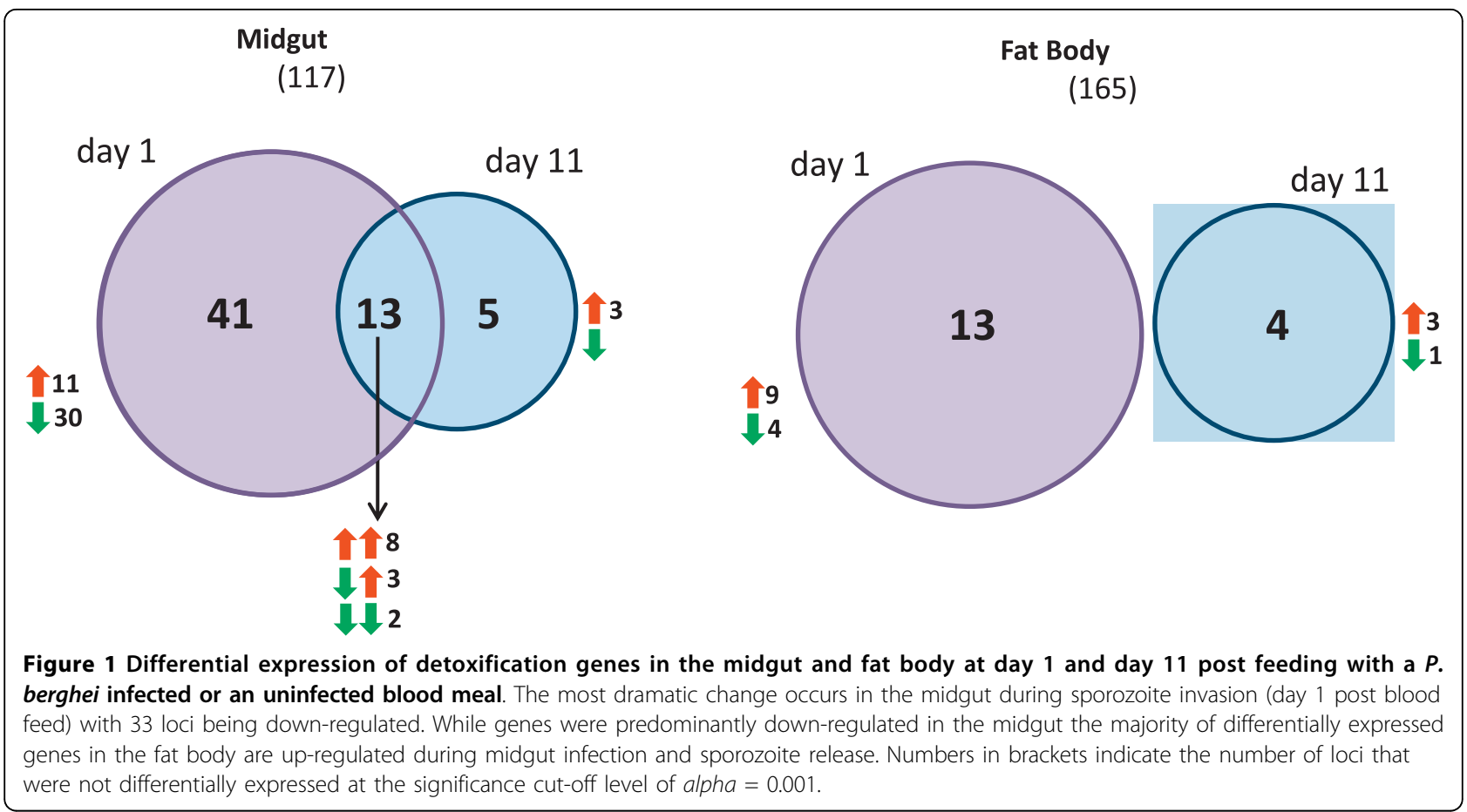

\section{Genes differentially expressed in infected versus} uninfected mosquitoes 11 days post blood meal

At this time point, when sporozoites are released from oocysts to the hemocoel a less pronounced effect on the transcript levels of detoxification genes was observed as compared to midgut invasion (Table 1). Two of the genes up-regulated on day 11, CYP4H25 and CYP4H15, were down-regulated at day 1 (Table 1 and 2), suggesting that their suppression is linked to the invasion of the midgut epithelium by the parasite, while their upregulation on day 11 may be associated with subtle changes in midgut structure as sporozoites are leaving oocysts. GST01 was up-regulated at both time points (Table 1 and 2) which indicates that this enzyme is directly involved in the response to parasites at both stages. Although at this stage the fat body would have had direct contact with parasites or at least molecules released by parasites during midgut egress, the transcriptional response in the fat body was more pronounced at day 1 than on day 11 post infection. CYP6M2 was down-regulated on day 11 but was upregulated at day 1 (Table 1 and 2), indicating that this CYP responds to particular events of the parasites life cycle.

Genes that show a different response between Plasmodium midgut epithelium invasion and release of sporozoites into the hemolymph

The interaction term between the two time points was investigated to compare responses to Plasmodium invasion of the midgut epithelium (day 1) and to the release of sporozoites into the hemolymph (11 days). Heat diagrams with the genes that presented significant positive (increased relative expression from day 1 to day 11) and negative interaction (decreased relative expression from day 1 to day 11) in midgut and fat body are shown in Figure 2. The number of genes under positive interaction was higher in the midgut while the opposite was seen in the fat body, reflecting the active site of infection.

ABC transporters from family c showed a strong negative interaction in the midgut and to a lesser extent in the fat body, implying that these cytoplasmic membrane transporters are important for infection control probably by transporting glutathione conjugates or lipid-derived eicosanoids that are known to be involved in insect response to infection [21].

The interaction analysis confirmed that there is a considerable difference between the gene expression levels between day 1 and day 11 in response to Plasmodium infection. There were a high number of genes that had different levels of expression in response to the ookinetes invasion of the midgut and in response to the release of sporozoites in the hemolymph, showing that these genes have the ability of changing their expression levels according with the time of infection.

In the midgut, the majority (69\%) of differentially expressed genes between day 11 and day 1 were the same both in uninfected and infected mosquitoes, as was the direction of change, indicating that these 
Table 1 Genes differentially expressed $(p<0.001)$ between infected and uninfected mosquitoes on day 1 after infection

\begin{tabular}{|c|c|c|c|c|c|}
\hline \multirow[t]{2}{*}{ Gene description } & \multirow[t]{2}{*}{ Probe name } & \multicolumn{4}{|l|}{1 day } \\
\hline & & Midgut fold & P-value & $\begin{array}{l}\text { Fat Body fold } \\
\text { Fold }\end{array}$ & $P$-value \\
\hline \multirow[t]{3}{*}{$A B C$ transporter } & ABCC10 & 2.38 & 0 & & \\
\hline & $\mathrm{ABCC} 11$ & 3.94 & 0 & & \\
\hline & $\mathrm{ABCC} 12$ & 1.77 & 0 & & \\
\hline Actin & Actin5C & 1.44 & 0.0008 & & \\
\hline \multirow[t]{24}{*}{ Cytochrome P450 monooxygenase } & CYP12F2 & -1.93 & 0 & 2.19 & 0 \\
\hline & CYP12F4 & -2.12 & 0 & & \\
\hline & CYP304B1 & -1.96 & 0 & & \\
\hline & CYP325H1 & -1.86 & 0.0003 & & \\
\hline & CYP4AR1 & -1.96 & 0.0004 & & \\
\hline & CYP4D15 & -2.70 & 0 & & \\
\hline & CYP4G17 & & & -1.26 & 0.00095 \\
\hline & CYP4H15 & -1.79 & 0 & & \\
\hline & CYP4H17 & -2.79 & 0 & & \\
\hline & CYP4H25 & -2.06 & 0 & & \\
\hline & CYP6AA1 & -1.82 & 0 & & \\
\hline & CYP6AA2 & -1.93 & 0 & & \\
\hline & CYP6AH1 & -2.44 & 0 & & \\
\hline & CYP6M1 & 1.60 & 0 & & \\
\hline & CYP6M2 & 4.23 & 0 & 2.73 & 0 \\
\hline & CYP6M3 & 1.62 & 0 & 2.10 & 0 \\
\hline & CYP6M4 & -1.29 & 0 & & \\
\hline & CYP6P1 & -1.38 & 0.0004 & & \\
\hline & CYP6Y1 & & & 1.61 & 0 \\
\hline & CYP6Y2 & 1.73 & 0 & & \\
\hline & CYP6Z2 & -2.80 & 0 & & \\
\hline & СҮР9J3 & -1.83 & 0 & & \\
\hline & CYP9L1 & -1.46 & 0 & & \\
\hline & CYP9M1 & 1.52 & 0.0004 & 1.43 & 0 \\
\hline \multirow[t]{2}{*}{ Esterase } & COEAE6G & -1.52 & 0.00099 & & \\
\hline & COEunkn & & & 2.19 & 0.0003 \\
\hline Glutathione peroxidase & GPX2B & & & 1.55 & 0 \\
\hline Glutaredoxin & GRX1 & 1.53 & 0 & & \\
\hline \multirow[t]{17}{*}{ Glutathione S-transferase } & GSTD1_5 & -1.56 & 0 & & \\
\hline & GSTD2 & -1.67 & 0 & & \\
\hline & GSTD3 & -1.55 & 0 & 2.17 & 0 \\
\hline & GSTD5 & 8.62 & 0.0006 & & \\
\hline & GSTD6 & -1.65 & 0 & & \\
\hline & GSTD11 & 1.48 & 0 & & \\
\hline & GSTD12 & -1.49 & 0 & & \\
\hline & GSTE2 & -1.57 & 0.0001 & & \\
\hline & GSTE3 & -1.51 & 0 & & \\
\hline & GSTE7 & -1.84 & 0 & & \\
\hline & GSTE8 & 1.57 & 0 & & \\
\hline & GSTO1 & 2.90 & 0 & & \\
\hline & GSTMS1 & -1.46 & 0 & & \\
\hline & GSTMS3 & -1.36 & 0 & & \\
\hline & GSTS1_2 & 2.08 & 0 & & \\
\hline & GSTT2 & -1.25 & 0.0002 & & \\
\hline & GSTU2 & 1.91 & 0 & & \\
\hline
\end{tabular}


Table 1: Genes differentially expressed $(p<0.001)$ between infected and uninfected mosquitoes on day 1 after infection (Continued)

\begin{tabular}{|c|c|c|c|c|c|}
\hline & GSTZ1 & & & -1.42 & 0 \\
\hline Midgut maltase-like protein & AGM1 & -1.59 & 0 & -1.59 & 0 \\
\hline NADPH P450 reductase & NADPH_P450_red & & & -1.53 & 0.0002 \\
\hline Nitrilase & NIT8537 & & & 2.54 & 0 \\
\hline \multirow[t]{2}{*}{ Ribosomal protein } & RPL19 & -1.37 & 0 & & \\
\hline & RPS26 & -1.53 & 0 & & \\
\hline Salivary gland protein & GSG8 & -1.43 & 0.0002 & & \\
\hline Superoxide dismutase & SOD2 & -1.98 & 0 & & \\
\hline \multirow[t]{2}{*}{ Thioredoxin peroxidase } & TPX3 & -1.47 & 0 & & \\
\hline & TPX4 & 1.26 & 0.0004 & & \\
\hline \multirow[t]{2}{*}{ Tubulin } & TubulinA & 1.85 & 0 & & \\
\hline & TubulinB & 8.76 & 0 & & \\
\hline
\end{tabular}

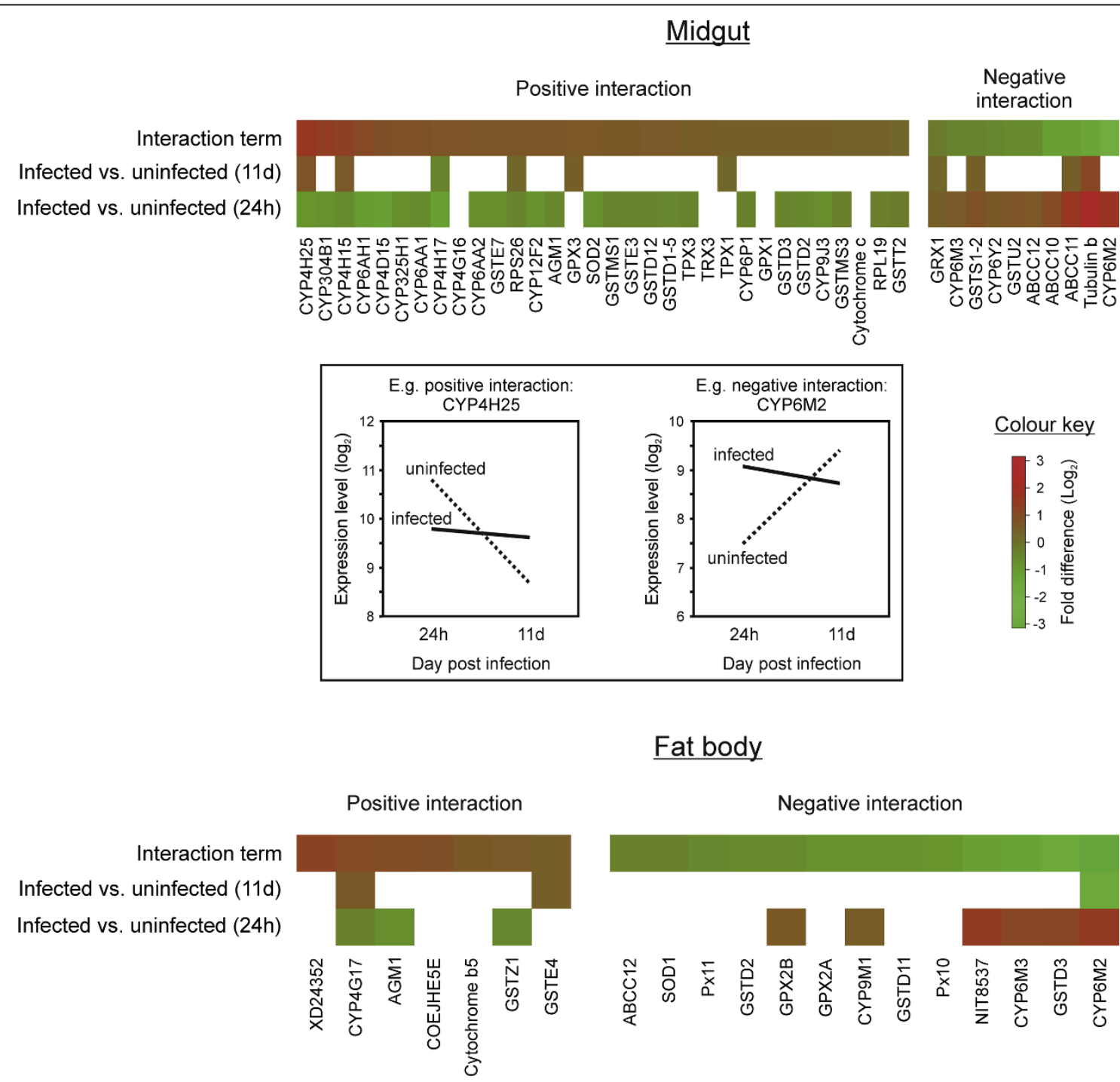

Figure 2 Heat diagrams showing genes that responded differently between the event of Plasmodium invasion into the midgut epithelium (day 1 post feeding) and the release of sporozoites into the hemolymph (day $\mathbf{1 1}$ post feeding). The loci are plotted in the top rows and arranged from most positive interaction on the left (red) to most negative interaction (green). Inset: Examples for a positive and a negative interaction term observed in the midgut. Only loci that showed a significant interaction term $(p<0.001)$ are plotted. 
Table 2 Genes differentially expressed $(p<0.001)$ between infected and uninfected mosquitoes on day 11 after infection

\begin{tabular}{|c|c|c|c|c|c|}
\hline \multirow[t]{2}{*}{ Gene description } & \multirow[t]{2}{*}{ Probe name } & \multicolumn{4}{|l|}{11 days } \\
\hline & & Midgut fold & $P$-value & Fat Body fold & $P$-value \\
\hline $\mathrm{ABC}$ transporter & $\mathrm{ABCC} 11$ & 1.47 & 0.0009 & & \\
\hline \multirow{7}{*}{ Cytochrome P450 monooxygenase } & CYP4G17 & & & 1.58 & 0 \\
\hline & CYP4H15 & 1.65 & 0 & & \\
\hline & CYP4H17 & -1.44 & 0.0002 & & \\
\hline & CYP4H19 & -1.65 & 0.0001 & & \\
\hline & CYP4H25 & 1.89 & 0.0004 & & \\
\hline & CYP6M2 & & & -2.91 & 0 \\
\hline & CYP6Z2 & -1.97 & 0 & & \\
\hline Glutathione peroxidase & GPX3 & 1.49 & 0 & & \\
\hline Glutaredoxin & GRX1 & 1.28 & 0 & & \\
\hline \multirow[t]{5}{*}{ Glutathione S-transferase } & GSTD10 & -1.65 & 0.0008 & & \\
\hline & GSTD11 & 1.70 & 0 & & \\
\hline & GSTE4 & & & 1.35 & 0.0003 \\
\hline & GSTO1 & 2.22 & 0 & & \\
\hline & GSTS1_2 & 1.43 & 0 & & \\
\hline Ribosomal protein & RPS26 & 1.23 & 0 & & \\
\hline \multirow[t]{3}{*}{ Thioredoxin peroxidase } & TPX1 & 1.27 & 0.0004 & & \\
\hline & $\mathrm{TPX} 2$ & 1.34 & 0 & & \\
\hline & TPX4 & 1.55 & 0 & 1.65 & 0.0001 \\
\hline \multirow[t]{2}{*}{ Tubulin } & TubulinA & 1.55 & 0 & & \\
\hline & TubulinB & 2.61 & 0 & & \\
\hline
\end{tabular}

genes were responding mainly to the blood meal, as it represents a strong oxidative insult. However, this total concordance was not observed in the fat body where only $26 \%$ of genes were regulated in the same direction between infected and uninfected while $38 \%$ were regulated in opposite directions (see Table S2 in Additional file 2). The trend of expression of both tissues suggests that differences observed are due to fat body response to parasite released from the oocysts into the hemocoel.

The mosquito response to sporozoites in the hemolymph triggers effector mechanisms like melanization [1], and a burst of expression of genes encoding constituents of the immune system including the production of free radicals [12] that needs a counter detoxification reaction. After excluding genes similarly regulated in both infected and uninfected groups, fat body CYP genes were down-regulated, at day 11, as observed for the midgut at day 1. SOD2 was down-regulated and seems to be determinant for parasite control. TPX4 was up-regulated confirming its role on infection detoxification mediated by the fat body. The fat body has an important role in the detoxification and in the immune response of the mosquito on day 11 of infection when compared with day 1 post infection, which is not observed when we compare infected and uninfected mosquitoes on day 11 .

\section{Conclusions}

This study determined transcription profiles of detoxification enzymes during Plasmodium infection in A. gambiae, showing important changes in the expression of several detoxification enzymes, as well as membrane associated $\mathrm{ABC}$ transporters. Interestingly, genes coding for detoxification enzymes revealed a variable response, being differentially induced or repressed depending on the tissue and stage of infection.

Although the mechanism underlying these changes is presently unclear, this differential regulation of detoxification genes observed during Plasmodium infection may be due to 1) the increasing oxidative stress caused by the presence of the parasite; 2) the epithelium rearrangement involving alterations in cytoskeleton genes caused by the ookinetes invasion and the oocysts burst; or 3) a combination of both. A hypothetical scenario for the inter-relationship between infection and detoxifying molecules is depicted in Figure 3.

In contrast to the majority of differentially expressed P450s which were down-regulated in response to midgut invasion, CYP6M2 expression was induced in 
Day 1

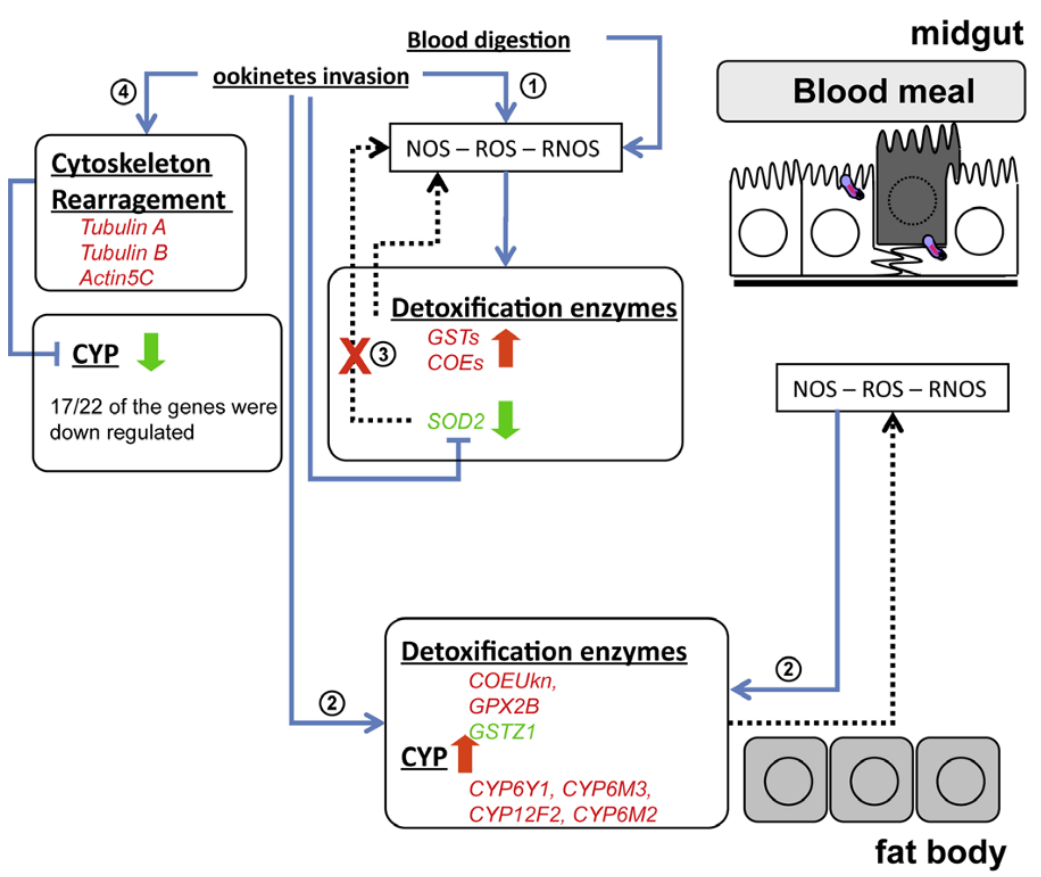

Day 11

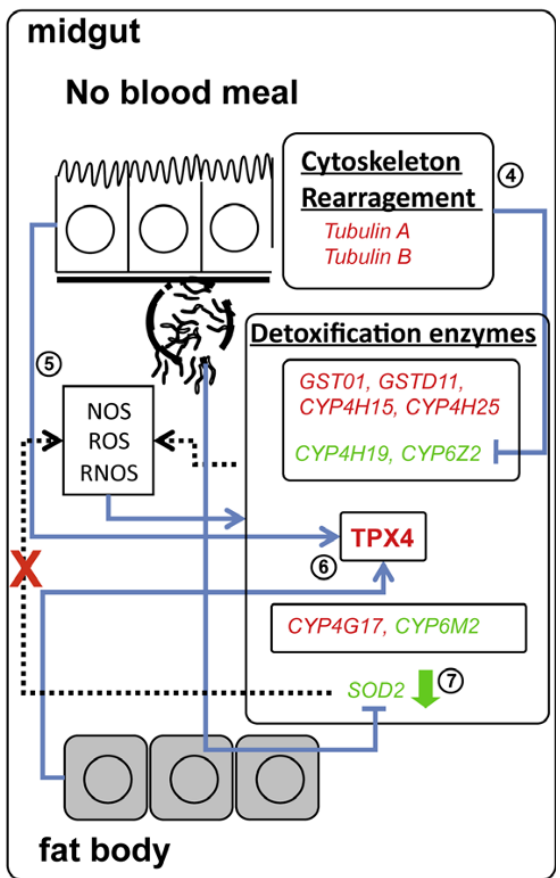

Figure 3 Hypothetical scenario of Anopheles gambiae detoxification response to Plasmodium berghei infection. Midgut and fat body genes up-regulated (red) and down-regulated (green) after infection at 2 different time points, day 1 (invasion of midgut epithelium by ookinetes) and day 11 (sporozoite egress from oocysts), and between the two events. At day 1, blood digestion and parasite invasion cause an increase in the ROS and RNOS that consequently increases the expression of detoxification enzymes (1). The parasite invasion and the ROS and RNOS also affect the fat body increasing the expression of detoxification enzymes in this tissue (2). At the same time midgut cells in response to parasite invasion suppresses the SOD expression (3) as a mechanism to eliminate parasites. Parasite invasion of midgut epithelium causes a massive cytoskeleton rearrangement that down regulates CYPs expression (4). On day 11, there is no blood digestion, but oocysts burst and sporozoites are released to the hemolymph. In the midgut the oocysts burst provokes a cytoskeleton rearrangement (4), as in day 1, that probably also down regulates CYPs expression in the midgut. While in the hemolymph sporozoites cause an increase in the ROS and RNOS that increase the detoxification enzymes expression in both midgut and fat body (5). Here, both midgut and fat body altered the expression of TPX4 (6), that is essential for hydrogen peroxide detoxification through the thioredoxin system. In the fat body sporozoites also provoke suppression of SOD expression (7).

response to $P$. berghei infection. This CYP is involved in resistance to pyrethroid insecticides $[17,18]$. This observation together with regulation of other genes, such as membrane $\mathrm{ABC}$ transporters involved in xenobiotic elimination, lead us to speculate that there might be an association between the response to Plasmodium infection and insecticide resistance, enhancing the importance of further studying their interaction.

\section{Methods}

\section{Mosquitoes}

A. gambiae s.s. (molecular $\mathrm{M}$ form) of the Yaoundé strain mosquitoes were reared at $26^{\circ} \mathrm{C}$ and $75 \%$ relative humidity on a $12 / 12$ hours light/dark cycle. Adult mosquitoes were maintained on $10 \%$ glucose solution until blood feeding.

\section{P. berghei infection of mosquitoes}

Female CD1 mice were intraperitoneally inoculated with $10^{7}$ P. berghei ANKA parasitised red blood cells. The levels of parasitaemia were measured from blood samples of the mouse tail using Giemsa-stained blood films. When the parasitaemia reached $10-20 \%$ and exflagellation was observed, mice were used to infect mosquitoes. Female mosquitoes were allowed to feed directly on naïve (control) and P. berghei infected mice up to one hour, with regular monitoring to certify mice were anesthetised. Fully engorged mosquitoes were kept at $19-21^{\circ} \mathrm{C}$ and $80 \%$ relative humidity for P. berghei development. The maintenance and care of experimental animals complied with portaria $n^{\circ} 1005 / 92$ from 23 rd October and was approved by the Divisão Geral de Veterinaria, Portugal. 


\section{Tissue collection}

Mosquito midguts and abdominal walls containing fat body tissues were collected from pools of 40 sibling mosquitoes at day 1 and on day 11 after the blood meal. This procedure was repeated to obtain 3 independent replicates. Tissues were dissected from mosquitoes submerged in ice-cold phosphate-buffered saline (PBS) that was prepared with DEPC-treated water and transferred to ice-cold RNAlater (Ambion). After incubation at $4^{\circ} \mathrm{C}$ over night any excess RNAlater was removed and samples were stored at $-20^{\circ} \mathrm{C}$ until RNA extraction. On day 11 post infection mosquito midguts were also collected to determine infection rate (number of infected mosquitoes over total number of mosquitoes observed).

\section{Microarray analysis}

Protocols for RNA extraction, amplification and labelling with fluorescent dyes are described in [22]. Fluorescent Cy3- and Cy5-labelled targets were hybridised to the latest version of the A. gambiae detox chip [23] (ArrayExpress accession AMEXP-863). The features on this version of the detox chip probe for 103 cytochrome P450s, 31 esterases, 35 glutathione S-transferases and 85 additional loci coding for enzymes such as peroxidases, reductases, superoxide dismutases, ATP-binding cassette transporters, tissue specific genes and housekeeping genes.

Two separate microarray experiments were conducted; one for the RNA pools obtained from midguts and another one for RNA extracted from fat body tissues. Each experiment followed a $2 \times 2$ factorial design in which the first factor was time and the second one was infection status. Each factor was measured at two levels; at one and eleven days post blood meal and from female mosquitoes that were either fed with Plasmodium-infected or uninfected blood. Factors and levels were combined constituting a total of four measurements. Each combination was repeated three times with tissues from 40 individuals pooled for RNA isolation per replicate (see Figure S2 in Additional file 4).

After scanning of raw signal intensities and visual spot inspection in GenePix Pro 5.1 software (Axon Instruments) data were exported to limma (version 2.9). Limma, part of the Bioconductor project [24], is a bioinformatics package for the analysis of linear models in microarray experiments [25] implemented in $\mathrm{R}$ http://www.r-project.org. Here, median spot and background intensities from the red (Cy5) and green (Cy3) channels were analysed. Any spot with a saturated signal in either the green or the red channel was excluded from the statistical analysis. For each spot, background intensities were first subtracted from the foreground intensities. To generate positive corrected intensities any intensity that was less than 0.5 after background subtraction was reset to 0.5 . Backgroundcorrected intensities from each spot were then transformed to intensity log-fold changes, $M=\log _{2}($ red $)$ $\log _{2}$ (green), and their geometrical means, $\mathrm{A}=\left[\log _{2}\right.$ (red) $+\log _{2}$ (green)]/2. Within each array, $M$-values for each spot were subsequently normalized as a function of $A$ using the loess scatter plot smoothing function implemented in limma. In the normalization step the calibration spots on the detox chip were included too. The detox chip contains 40 calibration spots representing a 1:1 dilution series over a concentration gradient from $1 \mathrm{pg}$ to $30 \mathrm{ng}$ per $2 \mu \mathrm{l}$ of added mRNA spike-in mix).

For the statistical analysis of the microarray experiments limma employs a linear model approach whereby linear models are fitted to the normalised data for each locus probed by the array $[25,26]$. Because each unique probe is spotted four times onto the detox chip we took advantage of the pooled correlation method implemented in limma to make full use of the replicate spots [27]. Contrasts, linear combinations of the coefficients, were then tested for significance. The contrasts tested between factor levels (time and infection status) and the interaction term (time $\times$ infection status) are given in Figure S2 (Additional file 4). To assess differential expression limma uses an empirical Bayes method to moderate the standard errors of the estimated log-fold changes [26]. This approach results in more stable inference and improved power, especially for experiments with small numbers of arrays [28]. $P$-values obtained from the $t$ tests (with the moderated $t$-statistic) were adjusted for multiple testing adopting the approach of Benjamini and Hochberg [25,29]. In order to define a set of differentially expressed genes only hits with an adjusted $p$-value below the level of significance, $\alpha=0.001$, were considered.

All microarray data have been deposited in ArrayExpress (ArrayExpress accession E-MTAB-195).

\section{Quantitative RT-PCR}

To validate microarray data a subset of 20 differentially expressed genes (see Table S2 in Addditional file 2) were chosen and their expression levels measured by multiplexed quantitative RT-PCR. The same RNA pools used in the microarray experiment served as target RNA in the PCR. The Beckman Coulter GeXP system was used to quantify the expression of these genes and the ribosomal protein RPS7-encoding gene [VectorBase: AGAP010592] was used for normalisation as described in [22]. PCR primer sequences are given in Table S3 (see Additional file 5). 
Additional file 1: Table S1. Infection rate and oocyst load of A. gambiae infected with $P$. berghei used for the microarray experiments.

Additional file 2: Table S2. List of all the genes differentially expressed $(p<0.001)$ represented on the Detox chip including fold change in expression and $p$-values.

Additional file 3: Figure S1. Validation of the DNA microarray analysis using quantitative RT-PCR. The mean expression values for midgut genes (A) and fat body genes (B) obtained by microarray analysis were plotted against the corresponding mean expression values obtained with quantitative RT-PCR. A high level of consistency between the two datasets was demonstrated by the Pearson correlation coefficient $(P=$ $0.884)$ for midgut and $(P=0.85)$ for fat body and best-fit linearregression analysis $\left(R^{2}=0.7814\right)$ for midgut and $\left(R^{2}=0.7228\right)$ for fat body.

Additional file 4: Figure S2. Design of the microarray experiments. The experiments for midgut and fat body tissues followed the same layout. The boxes of the graphs represent RNA extracted from pools of 40 individuals and the arrows the microarrays to which labelled target RNA was co-hybridized. The tails of the arrows represent the samples that were labelled with a green (Cy3) and the heads those samples that were labelled with a red (Cy5) fluorescent dye. For the design matrix in limma, the samples from uninfected tissues collected 1 day post infection were set as the reference pool (shaded boxes). After fitting linear models the contrasts shown below the diagram were constructed for hypothesis testing of specific comparisons between RNA pools. For each of the three biological blocks (replicates 1 to 3 ) and factor combination a separate coefficient was included in the design matrix. The contrasts were extracted by taking the average of the three comparisons.

Additional file 5: Table S3. Sequences of oligonucleotide primers used in quantitative RT-PCR validation experiments.

\section{Acknowledgements}

This work was partially supported by Fundação para a Ciência e a Tecnologia (FCT), trough research funds from project POCTI/IMI/59489/2004 $\mathrm{RF}$ is a recipient of a FCT grant (SFRH/BD/28024/2006).

\section{Author details}

'Centro de Malária e Outras Doenças Tropicais, UEl Malária, Instituto de Higiene e Medicina Tropical, Universidade Nova de Lisboa, Rua da Junqueira, 96, 1349-008 Lisbon, Portugal. ² Vector Group, Liverpool School of Tropical Medicine, Liverpool, L3 5QA, UK. 'Vector Control Unit, Medical Department, Swiss Tropical and Public Health Institute, $\mathrm{CH}-4002$ Basel, Switzerland. ${ }^{4}$ University of Basel, $\mathrm{CH}-4003$ Basel, Switzerland. ${ }^{5}$ Centro de Biomedicina Molecular e Estrutural (CBME), Instituto de Biotecnologia e Bioengenharia (IBB-LA), Universidade do Algarve, Faro, Portugal.

\section{Authors' contributions}

$\mathrm{RF}$ and PM performed the experiments; RF, PM and HS analyzed and interpreted the data; RF, PM, HR and HS wrote the paper. RF, PM, HS and VR conceived and designed the experiments. All authors read and approved the final manuscript.

\section{Received: 6 November 2009 Accepted: 19 May 2010}

Published: 19 May 2010

\section{References}

1. Kumar S, Christophides GK, Cantera R, Charles B, Han YS, Meister S, Dimopoulos G, Kafatos FC, Barillas-Mury C: The role of reactive oxygen species on Plasmodium melanotic encapsulation in Anopheles gambiae. Proc Natl Acad Sci USA 2003, 100:14139-14144.

2. Vlachou D, Schlegelmilch T, Christophides GK, Kafatos FC: Functional genomic analysis of midgut epithelial responses in Anopheles during Plasmodium invasion. Curr Biol 2005, 15:1185-1195.

3. Molina-Cruz A, DeJong RJ, Charles B, Gupta L, Kumar S, JaramilloGutierrez G, Barillas-Mury C: Reactive oxygen species modulate Anopheles gambiae immunity against bacteria and Plasmodium. J Biol Chem 2008, 283:3217-3223.

4. Ranson $\mathrm{H}$, Hemingway J: Mosquito glutathione transferases. Methods Enzymol 2005, 401:226-241.

5. Ortelli F, Rossiter LC, Vontas J, Ranson H, Hemingway J: Heterologous expression of four glutathione transferase genes genetically linked to a major insecticide-resistance locus from the malaria vector Anopheles gambiae. Biochem J 2003, 373:957-963.

6. Vontas JG, Small GJ, Hemingway J: Glutathione S-transferases as antioxidant defence agents confer pyrethroid resistance in Nilaparvata lugens. Biochem J 2001, 357:65-72.

7. Morgan ET: Regulation of cytochromes P450 during inflammation and infection. Drug Metab Rev 1997, 29:1129-1188.

8. Aguilar R, Das S, Dong Y, Dimopoulos G: Continuous exposure to Plasmodium results in decreased susceptibility and transcriptomic divergence of the Anopheles gambiae immune system. BMC Genomics 2007, 8:451

9. Baton LA, Robertson A, Warr E, Strand MR, Dimopoulos G: Genome-wide transcriptomic profiling of Anopheles gambiae hemocytes reveals pathogen-specific signatures upon bacterial challenge and Plasmodium berghei infection. BMC Genomics 2009, 10:257.

10. Dong Y, Aguilar R, Xi Z, Warr E, Mongin E, Dimopoulos G: Anopheles gambiae immune responses to human and rodent Plasmodium parasite species. PLoS Pathog 2006, 2:e52.

11. Feyereisen R: Insect P450 enzymes. Annu Rev Entomol 1999, 44:507-533.

12. Dimopoulos $G$, Seeley $D$, Wolf $A$, Kafatos FC: Malaria infection of the mosquito Anopheles gambiae activates immune-responsive genes during critical transition stages of the parasite life cycle. EMBO J 1998, 17:6115-6123.

13. Han YS, Thompson J, Kafatos FC, Barillas-Mury C: Molecular interactions between Anopheles stephensi midgut cells and Plasmodium berghei: the time bomb theory of ookinete invasion of mosquitoes. EMBO J 2000, 19:6030-6040.

14. Luckhart S, Vodovotz Y, Cui L, Rosenberg R: The mosquito Anopheles stephensi limits malaria parasite development with inducible synthesis of nitric oxide. Proc Natl Acad Sci USA 1998, 95:5700-5705.

15. Peterson TM, Gow AJ, Luckhart S: Nitric oxide metabolites induced in Anopheles stephensi control malaria parasite infection. Free Radic Biol Med 2007, 42:132-142.

16. Hara H, Adachi T: Contribution of hepatocyte nuclear factor-4 to downregulation of CYP2D6 gene expression by nitric oxide. Mol Pharmacol 2002, 61:194-200.

17. Djouaka RF, Bakare AA, Coulibaly ON, Akogbeto MC, Ranson H, Hemingway J, Strode C: Expression of the cytochrome P450s, CYP6P3 and CYP6M2 are significantly elevated in multiple pyrethroid resistant populations of Anopheles gambiae s.s. from Southern Benin and Nigeria. BMC Genomics 2008, 9:538

18. Muller P, Donnelly MJ, Ranson H: Transcription profiling of a recently colonised pyrethroid resistant Anopheles gambiae strain from Ghana. BMC Genomics 2007, 8:36.

19. Antoun J, Goulitquer S, Amet Y, Dreano Y, Salaun JP, Corcos L, PléeGautier E: CYP4F3B is induced by PGA1 in human liver cells: a regulation of the 20-HETE synthesis. J Lipid Res 2008, 49:2135-2141.

20. Dvorak Z, Ulrichova J, Modriansky M: Role of microtubules network in CYP genes expression. Curr Drug Metab 2005, 6:545-552.

21. Stanley D: Prostaglandins and other eicosanoids in insects: biological significance. Annu Rev Entomol 2006, 51:25-44.

22. Muller P, Chouaibou M, Pignatelli P, Etang J, Walker ED, Donnelly MJ, Simard F, Ranson H: Pyrethroid tolerance is associated with elevated expression of antioxidants and agricultural practice in Anopheles arabiensis sampled from an area of cotton fields in Northern Cameroon. Mol Ecol 2008, 17:1145-1155.

23. David JP, Strode C, Vontas J, Nikou D, Vaughan A, Pignatelli PM, Louis C, Hemingway J, Ranson $\mathrm{H}$ : The Anopheles gambiae detoxification chip: a highly specific microarray to study metabolic-based insecticide resistance in malaria vectors. Proc Natl Acad Sci USA 2005, 102:4080-4084.

24. Gentleman RC, Carey VJ, Bates DM, Bolstad B, Dettling M, Dudoit S, Ellis B, Gautier L, Ge Y, Gentry J, Hornik K, Hothorn T, Huber W, lacus S, Irizarry R, Leisch F, Li C, Maechler M, Rossini AJ, Sawitzki G, Smith C, Smyth G, 
Tierney L, Yang JY, Zhang J: Bioconductor: open software development for computational biology and bioinformatics. Genome Biol 2004, 5:R80.

25. Smith GK: Limma: linear models for microarray data. Bioinformatics and Computational Biology Solutions using $R$ and Bioconductor New York: SpringerGentleman R, Carey V, Dudoit S, Irizarry R, Huber W 2005, 397-420

26. Smyth GK: Linear models and empirical bayes methods for assessing differential expression in microarray experiments. Stat Appl Genet Mol Biol 2004, 3, Article3.

27. Smyth GK, Michaud J, Scott HS: Use of within-array replicate spots for assessing differential expression in microarray experiments. Bioinformatics 2005, 21:2067-2075.

28. Smyth GK, Yang YH, Speed T: Statistical issues in CDNA microarray data analysis. Methods Mol Biol 2003, 224:111-136.

29. Benjamini Y, Drai D, Elmer G, Kafkafi N, Golani I: Controlling the false discovery rate in behavior genetics research. Behav Brain Res 2001, 125:279-284

doi:10.1186/1471-2164-11-312

Cite this article as: Félix et al:: Plasmodium infection alters Anopheles gambiae detoxification gene expression. BMC Genomics 2010 11:312.

\section{Submit your next manuscript to BioMed Central} and take full advantage of:

- Convenient online submission

- Thorough peer review

- No space constraints or color figure charges

- Immediate publication on acceptance

- Inclusion in PubMed, CAS, Scopus and Google Scholar

- Research which is freely available for redistribution

Submit your manuscript at www.biomedcentral.com/submit 